\title{
Comparative Assessment of Environmental Effects by LCA Method of Natural Aggregates Extraction Processes and Production of Their Substitutes from Waste in the City Mining System
}

\author{
Bartosz Zegardło' \\ 1 Siedlce University of Natural Sciences and Humanities, Research Team of Quantitative Methods and Spatial \\ Management, B. Prusa 14, 08-110 Siedlce, Poland \\ * Corresponding author's e-mail: bart.z@wp.pl
}

\begin{abstract}
This paper is devoted to the topic of obtaining substitutes for natural aggregates in the city mining system. An article draws attention to the adverse effects of natural aggregate mining on the environment and presents its alternative based on processing waste mineral materials into aggregate form. Referring to the examples presented in the literature, technical possibilities of producing recycled aggregates from waste concrete, ceramic and glass materials were indicated. The system of collecting waste directly from potential users was also presented and the adaptation processes which waste must undergo were described. The research part of the study consisted of analyses of the environmental impact of the processes of obtaining natural aggregates and production of their substitutes from waste in the city mining system. The LCA (life cycle assessment) method was used to carry out the analyses. Using the available databases, calculations of the environmental impact of both processes were performed. The comparison of the obtained results proved that despite the unfavourable additional environmental effects caused by the adaptation processes required for waste, the environmental impact of the rational production of aggregates from recyclates is favourable, and such activities should be recommended for implementation in the industry.
\end{abstract}

Keywords: aggregate substitutes, ceramic waste, glass waste, environmental impact, life cycle assessment.

\section{INTRODUCTION}

Since the great industrial revolution, the quality of life of societies has been steadily improving. Thanks to the work of machines many products have become cheaper and more easily accessible. In spite of the many successes in this field, however, it is increasingly becoming apparent that these processes have resulted in a significant impoverishment and deterioration of the quality of the natural environment. The cause of this state of affairs is not only the excessive use of substrates for the production of new goods, which reduces natural resources. Much more serious consequences are caused by the fact that easy availability and low price of many products cause that they are abandoned by users before they are actually used up.

In almost all sectors of the economy, whether it is construction, knitting or automotive industry, items which have not lost their usefulness are sent to landfills to be replaced by new ones, e.g. only for aesthetic reasons. Over-consumption increases the demand for new products, producers meet the demand by drawing further resources from the environment, and the amount of products deposited in landfills continues to grow.

As a result, the main problem of the modern world has become a global problem of waste management. Concepts of sustainable development proclaiming the "RRR" principles, i.e. reduce, reuse, recycle, direct the eyes of the society towards the above mentioned problem. Numerous campaigns have been launched with the aim of reducing consumption of goods as well as searching for alternative ways of managing exhausted goods. As a result of these actions, the term "urban mining" was introduced. In the original version of this concept, attention was focused on the possibility 
of recovering metals, especially precious ones, from electronic products which were considered depleted and ended up in landfills. However, more often, as promoted by the author of this article, the concept is being extended to a much wider range of waste, in which many other, also non-ferrous, minerals are located. Examples include concrete, ceramic and glass waste. Rational reuse of such materials could be an alternative to obtaining natural aggregates. It is more often pointed out that due to increasing construction consumption traditional acquisition of mineral aggregates causes degradation of landscape, disturbance of groundwater system and also causes that in some areas aggregate resources have already been depleted or are quickly approaching depletion.

The response of the scientific community to the above issues are numerous research works devoted to the analysis of the possibility of using recyclates in the function of natural aggregates. The most widespread trend is the use of concrete rubble for these purposes [Małaszkiewicz and Pawluczuk, 2006]. Despite the possibility of using this type of recyclates even at the place where they were obtained and only after crushing, such action encounters many limitations. They especially concern the quality of input and output parameters of composites [Hare and Golębiowska, 2014]. Depending on the technical parameters of the recycled material it can get composites of different quality [Anin et al., 1996]. There are strong influences of the characteristics of the waste on the characteristics of the concretes [Ajdukiewicz and Kliszczewicz, 2012].

The key parameter of recycled-concrete aggregate that most research teams refer is its density. It is usually lower than that of natural aggregate especially due to the low quality cementitious stone present in the waste. This characteristic in turn affects the reduced strength of the recyclate and allows water penetration into its volume, resulting in reduced resistance to cyclic freezing/thawing [Ahn and Kishi, 2010]. Another significant problem is the contact zone of the virgin aggregate with the virgin cementitious stone [Jevtic et al., 2012]. A poor quality contact zone is a weak link that adversely affects the performance of the final composite [Hansen and Narud, 2003; Rao et al., 2007]. Similarly, high air content is an unfavorable characteristic of the recycled material. It increases water consumption and thus necessitates the use of more cement compared to composites based on traditional aggregates [CCANZ Technical Report, 2011].
Slightly different are the results of studies on aggregates made of red ceramics. They require similar amount of work in the aspect of their collection, selection and processing as concrete rubble. Construction sites recovered by demolition of buildings, for example, brick abound in large quantities of recyclates, and due to the fact that these wastes are more homogeneous than concrete rubble and have more favorable technical characteristics, it is noted that such actions fit into the ideas of sustainable development. The use of shredded ceramics for concrete dates back to ancient times [Ziolkowski, 2009], and nowadays, in the face of numerous demolitions of buildings made of ceramics, research work is carried out on this issue [Senthamarai et al., 2011].

Most of the works carried out do not focus on obtaining special properties of recycled concretes, and the main purpose is to dispose of the waste [De Brito et al., 2005]. The authors present in them both the problems of waste generation and the causes and difficulties of its reuse [[Pacheco-Torgal and Jalali, 2010; Debieb at al., 2008]. The researchers also pay attention to the impossibility of spontaneous biodegradation of ceramic waste [Devenny and Khalaf, 1999]. Presented papers concern both the use of waste in the form of masonry rubble [Khalf et al., 2004], clinker [Khalloo, 1994] and fine aggregate [Khatie and Jamal, 2005]. Results of presented works underline positive influence of such operations on environment both from waste utilization as well as reduction of consumption and extraction of natural aggregates [Levy et al., 2004; Mansur and Wee, 1999].

A relatively new trend in obtaining and reusing waste materials is the use of glass materials and technical ceramics as substitutes for aggregates. They require more work in the aspect of their collection, selection and processing. Construction sites, even if recovered by demolition, do not have sufficient quantities of recyclates, as is the case with concrete rubble or red ceramics. For the sake of the most rational management of this waste it is recommended to introduce it into circulation by depositing it directly at entrepreneurs - concrete producers. This type of system is in line with the urban mining principle, especially because ceramic and glass waste are more homogeneous than concrete rubble and have more beneficial technical characteristics than it. Even long-term collection of this type of waste results in the accumulation of resources that are 
homogeneous in structure and have more favourable characteristics than traditional aggregates. Processing them by the concrete producer using crushers is the only necessary adaptation process. Numerous research works present many advantages of aggregates produced from this type of waste. The advantages over aggregates made of concrete and red ceramics refer to both the mechanical properties and the microstructure of the obtained composites, as well as the environmental benefits of the presented solutions, especially that in the case of high-quality recyclates no additional amounts of cement are required in the preparation of new composites [Guerra et al., 2009; Medina et al. 2012; Lopez et al., 2007]. More detailed analyses present the results of rheological and calorimetric tests of the mentioned recycled composites [Medina et al., 2013]. Numerous works prove that this type of composites can have special features due to the use of waste materials. Among them appear: high abrasion resistance [Halicka et al. 2013], ultra high strength [Zegardło et al. 2016], high chemical resistance [Ogrodnik et al. 2017a], heat accumulation ability [Ogrodnik et al. 2017b], resistance to high temperatures [Zegardło et al. 2018a] or resistance to sewage environment [Zegardło et al., 2018b] can be observed. All these prove that these types of aggregates have technical characteristics more favorable than natural aggregates, and composites obtained with their participation are of better quality than with traditional aggregates.

The above described approach to segregation and collection of different types of waste in urban areas is very beneficial in many environmental aspects. Due to the possibility of reusing waste almost at its place of origin, many adverse environmental impacts of recycling processes are reduced. Often this fact goes unnoticed and ignored, and waste is sent to landfills far from urban areas. On the other hand, it should be noted that irrationally carried out processes of reuse of many materials are not only not economically justified, but also have the opposite effect on the environment than expected. It is often forgotten here that processing-adaptive processes often also consume natural resources and cause e.g. emission of pollutants into the environment. Processes such as transport, sorting, washing, grinding have a negative impact on the environment. Powering up vehicles and machines impoverishes the environment with energy resources and causes emission of exhaust fumes, washing uses water resources and introduces detergents into the environment, grinding causes wear and tear of equipment components, the production of which requires reuse of raw materials. These examples are only a fraction of the effects that these processes actually have on the environment.

Taking into account both the technical feasibility of using waste as aggregate substitutes and the potential negative effects of recycling aggregate adaptation processes, this paper compares the environmental impact of the two aggregate extraction systems. The first system was the natural aggregate extraction system considering the extraction of natural resources, the processes of extracting them from the deposit and transporting them to the concrete producer. The second system was the extraction of aggregates from deposited mineral waste at the producer. The adaptation process assumed only the grinding of the waste. The LCA method was used to perform the calculations.

\section{RESEARCH METHODOLOGY}

The life cycle assessment (LCA) method is a research system whose aim is to evaluate the environmental impact of various, often complex processes, which influence the natural environment to a large extent [Kowalski et al. 2007]. Its specific aim is to detect and indicate possible risks. The main idea of this method is not only to determine the final result of the process under study, but also to estimate and evaluate the consequences of the whole process for many criteria of environmental threats. The course of conducting the tests is standardized and defined by the standards [PN-EN ISO 14040-14043]. The ISO 14040 standard defines the methodology of environmental impact assessment, indicating four different phases of research. The first phase is the purpose and scope phase, which sets the context for the study. The second phase is the dataset analysis (LCI), which determines the raw materials that are entering the system and identifies the emissions and wastes entering the environment. The third phase is the impact assessment phase, which identifies potential environmental impacts. The fourth and final phase is the interpretation phase, in which the information from the results is evaluated [ISO 14040: 2006].

To conduct the research and analysis presented in this paper, openLCA 1.10 .3 software was used. It is an open source software whose main 
task is to support widely understood sustainable development. It cooperates with publicly available databases concerning various processes. The databases are continuously updated and shared by numerous users of the system. OpenLCA enables calculations as well as detailed analysis with identification of all factors. It has the possibility to import and export data as well as the uncomplicated sharing of models.

Based on the normative guidelines, the context of the study was clarified in the first stage of work in the purpose and scope phase. The environmental implications were conducted for a sample town located in eastern Poland with a population of approximately 70,000 . It was determined that the purpose of the analyses would be to compare the environmental effects of the production of aggregates for concrete. It was assumed that two series of studies will be carried out and the comparative analysis of obtained results will be made. The first study of the first series was conducted for the process of obtaining natural aggregates - and it was designated with the symbol: I aggNAT. It was assumed that the aggregate will be drawn from a deposit $30 \mathrm{~km}$ away from the concrete production site. This study considered the impact of both the aggregate extraction process, transport and depletion of the deposit. In the second study of this series, it was assumed that recycled aggregates would be deposited directly at the concrete producer by demolition companies (I aggREC). This was considered to be the optimal solution for demolition company owners due to the similar location - urban demolition sites and companies -concrete producers. As it resulted from surveys conducted among entrepreneurs it is more favorable for both economic and logistical reasons especially due to the fact that landfills are located outside the city and depositing waste there is paid. The functional unit used for the calculations was $1 \mathrm{~kg}$ of aggregate.

In the second series of studies, the first study was identical to the first series and again consisted of calculating the environmental effects of natural aggregate production assuming aggregate transport at a distance of $30 \mathrm{~km}$. It was designated II aggNAT. The second study of the second series designated II aggREC+TRANS determined the environmental impact of the process of producing aggregate from recyclate assuming that it was deposited in a landfill and transported to an entrepreneur - concrete producer.

The second phase of the project was an analysis of the dataset that determined the raw materials that are entering the system and identified the emissions and waste entering the environment. This phase of the research used the ELCD_3_2_greendelt_v2_18_1 database. It identified all the raw materials, including those used as fuels and equipment depreciation, that both natural aggregate extraction and waste adjustment require. For the extraction of natural aggregates, the processes of segregation and washing of aggregates were also taken into account. For the assessment of the effects of production of recycled aggregates data were used as for the production of crushed aggregates. Figure 1 shows wastes that can be used as aggregate substitutes in the municipal mine system.

In the third phase of the research work, impact assessment was performed. In this part of

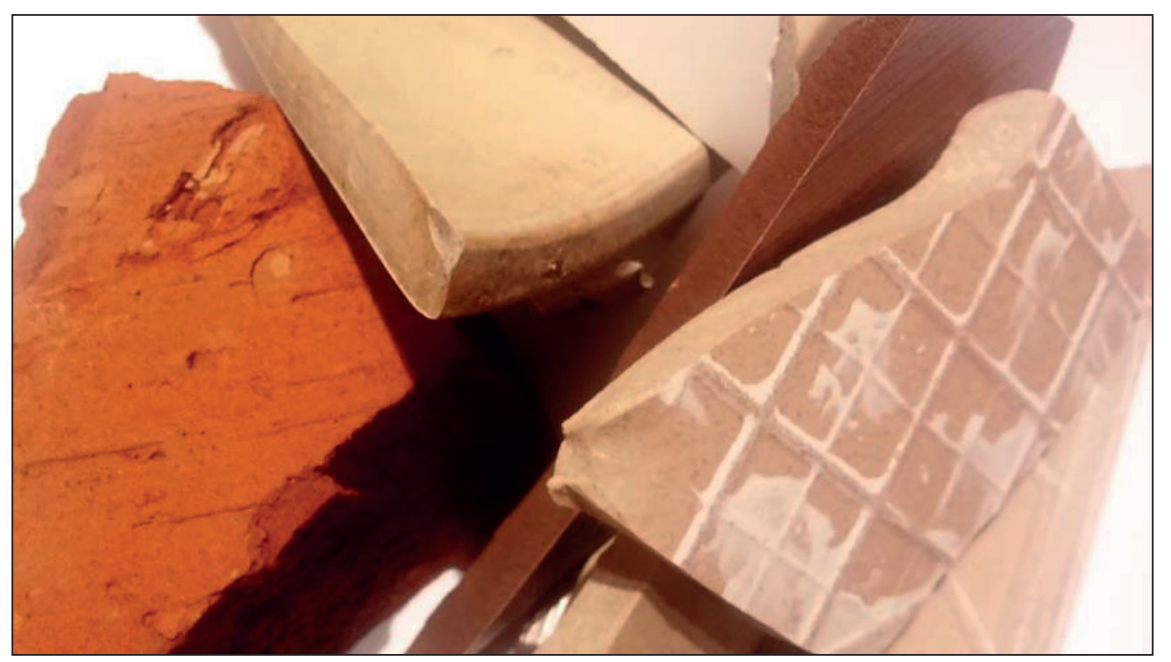

Figure 1. Wastes that can be used as aggregate substitutes in the municipal mine system - sanitary ceramics and ceramic floor and wall tiles 
the work, the values of the effects of the influence of given processes on the environment were calculated. For this purpose, two methods were used depending on the impact parameter under study. The first of the available methods was the method of the Institute of Environmental Engineering of Leiden University - CML. This method assessed the impact of the production of both types of aggregates on climate change, which was expressed in kilograms of $\mathrm{CO}_{2}$ equivalent introduced into the environment. Another parameter evaluated using this method was the amount of energy resource depletion expressed in MJ units. The last parameter examined by this method was human toxicity expressed in units of $\mathrm{kg}$ of 1,4-dihlorobenzene equivalent. The second method of environmental impact assessment was Ecological Scarcity Method (ESM). This method assessed the impact on the depletion of natural resources. It was expressed in UBP units, i.e. units of ecological scarcity. The total emission of pollutants to the air was assessed using the same method.

The fourth and final phase of the research work was the interpretation phase, in which the information from the results was compared and analyzed.

\section{RESULTS}

A summary of the results of the analyses I and II series of tests is included in Table 1. The results of the first phase of the study definitively proved the environmental benefits of producing natural aggregate substitutes from recyclates. All examined parameter values for natural aggregate production were higher than those calculated for recycled aggregate production. The impact on climate change, which was expressed in kilograms of $\mathrm{CO}_{2}$ equivalent introduced into the environment, was for the production of natural aggregates I aggNAT higher by $59 \%$ than the production of aggregates from recyclates deposited at the concrete producer. Similarly, the next parameter evaluated, the amount of energy resource depletion expressed in MJ units, was also 61\% higher for the production of natural aggregates than for recyclates. In terms of human toxicity expressed in units of $\mathrm{kg}$ of 1,4-dihlorobenzene equivalent, the production of natural aggregates presented a $78 \%$ higher value compared to the production of recycled aggregates. However, the greatest benefit for the environment was observed in the study of the parameter that was the depletion of natural resources, which was expressed in units of UBP, i.e. units of ecological scarcity. Here, the value assessed for the production of natural aggregates I aggNAT was 0.018 UBP, while for recyclates I aggREC was 0.0012 UBP and was therefore $93 \%$ lower than for natural aggregates. The last evaluated value, which was the total emission of pollutants into the air also expressed in UBP units was similarly lower for the production of aggregates from recyclates I aggREC and it was $49 \%$ lower than the value that was calculated for the production of traditional aggregates I aggNAT.

The results of the comparison of values obtained in the second series of studies were slightly different. The assessment of the environmental impact of the production of aggregate substitute from recyclates, taking into account their deposition in landfills and transport to the concrete producer II aggREC+TRANS, in some cases of the assessed effects was even less beneficial for the environment than the production of natural aggregates II aggNAT. The impact on climate change, expressed in kilograms of $\mathrm{CO}_{2}$ equivalent introduced into the environment, was for the production of natural aggregates II aggNAT 16\% lower than the production of aggregates from recyclates transported to the concrete producer. Another evaluated parameter - the amount of energy resource depletion expressed in MJ units was almost the same for both natural aggregates production and recyclates. The difference in the assessed values was only $1.5 \%$ in favour of recyclates. In terms of human toxicity expressed in units of $\mathrm{kg}$ 1,4-dihlorobenzene equivalent, the production of natural aggregates presented a lower value again. It was a small difference of about $3 \%$, but again in this aspect the production of natural aggregates proved to be more beneficial to the environment. In the study of the second series, invariably the greatest benefit for the environment was observed in the case of the study of the parameter which was the depletion of natural resources, which was expressed in UBP units, i.e. units of ecological scarcity. Here, the value assessed for the production of natural aggregates II aggNAT was $0.018 \mathrm{UBP}$, while for recyclates II aggREC+TRANS it was 0.00308 UBP and was therefore $83 \%$ lower than for natural aggregates. The last evaluated value, which was the total emission of pollutants into the air also expressed in UBP units when taking into account 
Table 1. Summary of the results of tests

\begin{tabular}{|c|c|c|c|c|c|c|c|}
\hline Lp. & $\begin{array}{c}\text { Test } \\
\text { method }\end{array}$ & Test value & Unit & $\begin{array}{c}\text { I } \\
\text { aggNAT }\end{array}$ & $\begin{array}{c}\text { I } \\
\text { aggREC }\end{array}$ & $\begin{array}{c}\text { II } \\
\text { aggNAT }\end{array}$ & $\begin{array}{c}\text { II } \\
\text { aggREC+TRANS }\end{array}$ \\
\hline 1 & $\mathrm{CML}$ & $\begin{array}{c}\text { Climate change } \\
\text { GWP 100 }\end{array}$ & $\mathrm{kg} \mathrm{CO}$ eq. & 0.02193 & 0.01379 & 0.02193 & 0.02611 \\
\hline 2 & $\mathrm{CML}$ & $\begin{array}{c}\text { Depletion of } \\
\text { resources }\end{array}$ & $\mathrm{MJ}$ & 0.2426 & 0.1507 & 0.2426 & 0.2462 \\
\hline 3 & $\mathrm{CML}$ & Human toxicity & $\begin{array}{c}\mathrm{kg} 1,4-\text {-dihlorobenzene } \\
\text { eq. }\end{array}$ & 0.0092 & 0.00518 & 0.0092 & 0.0094 \\
\hline 4 & $\mathrm{ESM}$ & Natural resources & UBP & 0.0181 & 0.0012 & 0.0181 & 0.00308 \\
\hline 5 & $\mathrm{ESM}$ & Emission to air & UBP & 6.2628 & 3.194 & 6.2628 & 6.388 \\
\hline
\end{tabular}

the transport of recyclates, was also similar to that calculated for natural aggregates. Nevertheless, the environmental impact here turned out to be more favorable for the production of natural aggregates. The difference in the values of the calculated parameters was about $2 \%$.

\section{CONCLUSIONS}

Taking into account the obtained results of the research work, it can be definitively stated that the process of obtaining aggregate substitutes from recyclates is certainly beneficial for the environment in the case of rational recycling. The ideas of urban mining promoting waste disposal in properly designated places in cities - as it has been suggested e.g. directly at concrete producers - bring only beneficial environmental effects in comparison to the production of natural aggregates.

The results of the second series of studies, on the other hand, prove the adverse environmental effects that are associated with irrational waste management. In spite of the technical possibilities of reuse, transport, collection and multiple shipments of recyclates result in negative environmental impacts. In some aspects such as climate change, human toxicity and emissions, the use of recyclates without rational management is less beneficial than the extraction of natural aggregates. Despite the saving of natural resources, such activities should not be undertaken.

Summarizing the results of the conducted analyses, it is worth recommending that waste collection processes be carried out directly at entrepreneurs who have the technical potential to utilize it. These systems are in line with the urban mining ideology, which assumes rational waste management and its processing almost in the place where it is created. Such systems have a beneficial influence on the environment. The presented methods of obtaining substitutes for natural aggregates give a chance to reduce the amount of aggregates obtained from natural resources. Such action limits landscape degradation, resource depletion and reduces environmental pollution.

\section{REFERENCES}

1. Ahn T., Kishi T. 2010. Crack self-healing behavior of cementitious composites incorporating various mineral admixtures. J. Adv. Concrete Technol., 8, 171-186.

2. Ajdukiewicz A., Kliszczewicz A. 2012. Ad hoc and rheological properties of structural concretes on recycled aggregates. Zeszyty Naukowe Politechniki Rzeszowskiej. Construction and Environmental Engineering, 3, 173-180.

3. Anink D., Boonstra C., Mak J. 1996. Handbook of Sustainable Building, An Environmental Preference Method for Selection of Materials for Use in Construction and Refurbishment, London.

4. CCANZ Technical Report 2011. Best practice guide for the use of recycled aggregates in new concrete. Cement \& Concrete Association of New Zealand.

5. De Brito J., Pereira J., Correia J.R. 2005. Mechanical behaviour of non-structural concrete made with recycled ceramic aggregates, Cement and Concrete Composites, 27, 429-433.

6. Debieb A., Farid S., Kenai S. 2008. The use of coarse and fine crushed bricks as aggregate in concrete. Construction and Building Materials, 22(5), 886-893.

7. Devenny A., KhalafF.M. 1999. Use of crushed brick as coarse aggregate in concrete. Masonry International, 12(3), 81-84.

8. Environmental Management-Life Cycle AssessmentPrinciples and Framework; ISO 14040: 2006; ISO: International Organization for Standardization Geneva.

9. Guerra I., et al 2009.. Eco-efficient concretes: The effects of using recycled ceramic material from 
sanitary installations on the mechanical properties of concrete. Waste management, 29(2), 643-646.

10. Halicka A., Ogrodnik P., Zegardło B., 2013. Using ceramic sanitary ware waste as concrete aggregate. Construction and Building Materials, 48, 295-305.

11. Hansen T.C., Narud H. 2003. Strength of recycled concrete made from crushed concrete coarse aggregate. Concrete International - Design and Construction, 5, 35-48.

12. Hare B., Golębiowska I. 2014 The future of concrete with recycled concrete aggregate, Inż. Ap. Chem., $53,6,390-392$.

13. Jevtić D., Zakić D., Savić A. 2012 . Achieving sustainability of concrete by recycling of solid waste materials. Mech. Test. Diagn., 1(2), 22-39.

14. Khalaf S., Fouad M., Devenny, Alan S. 2004. Recycling of demolished masonry rubble as coarse aggregate in concrete: review. Journal of materials in civil engineering, 16(4), 331-340.

15. Khalloo A. 1994. Properties of concrete using crushed clinker brick as coarse aggregate. ACI Materials Journal, 8, 91-94.

16. Khatie, Jamal M. 2005. Properties of concrete incorporating fine recycled aggregate. Cement and Concrete Research, 35(4), 763-769.

17. Kowalski Z., Kulczycka J., Góralczyk M. 2007. Ecological life cycle assessment of manufacturing processes (Ekologiczna ocena cyklu życia procesów wytwórczych) (LCA), Wydawnictwo Naukowe PWN, Warszawa.

18. Levy A., Salomon M., Paulo H. 2004. Durability of recycled aggregates concrete: a safe way to sustainable development. Cement and concrete research, 34(11), 1975-1980.

19. Lopez V., et al. 2007. Eco-efficient concretes: impact of the use of white ceramic powder on the mechanical properties of concrete. Biosystems Engineering, 96(4), 559-564.

20. Małaszkiewicz D., Pawluczuk E. 2006. The influence of recycled aggregate on selected technical properties of concrete,Prace Naukowe Instytutu Budownictwa Politechniki Wrocławskiej. Studia i Materiały, 87(18), 405-410.

21. Mansur M., Wee T. 1999. Crushed bricks as coarse aggregate for concrete. ACI Materials Journal, 1999, 96(4), 84-89.

22. Medina C., De Rojas M., Frias M. 2012. Reuse of sanitary ceramic wastes as coarse aggregate in eco-efficient concretes. cement and concrete composites, 34, 48-54.

23. Medina C., et al. 2013. Rheological and calorimetric behaviour of cements blended with containing ceramic sanitary ware and construction/demolition waste. Construction and Building Materials, 40, 822-831.
24. Medina C., Frias M., De Rojas M. 2012. Microstructure and properties of recycled concretes using ceramic sanitary ware industry waste as coarse aggregate. Construction and Building Materials, 31, 112-118.

25. Ogrodnik P., Zegardło B., Radzikowska M. 2017a. Use of post-production sanitary ceramic waste as a filler for cement composites with high chemical resistance, Chemical Industry, 96(5), 1100-1104.

26. Ogrodnik P., Zegardło B., Szeląg M. 2017b. The use of heat-resistant concrete made with ceramic sanitary ware waste for a thermal energy storage. Applied Sciences, 7(12), 1-16.

27. Pacheco-Torgal F., Jalali S. 2010. Reusing ceramic wastes in concrete, Construction and Building Materials, 24, 832-838.

28. PN-EN ISO 14040 Environmental management Life cycle assessment - Principles and structure, PKN, Warszawa 2000.

29. PN-EN ISO 14041 Environmental management Life cycle assessment - Objective and scope definition and set analysis, PKN, Warszawa 2000.

30. PN-EN ISO 14042 Environmental management Life cycle assessment - Impact assessment, PKN, Warszawa 2000.

31. PN-EN ISO 14043 Environmental management Life cycle assessment - Interpretation of life cycle, PKN, Warszawa 2000.

32. Rao A., Jha K.N., Misra S., 2007. Use of aggregates from recycled construction and demolition waste in concrete. Res. Conserv. Recycl., 50, 71-81.

33. Senthamarai R.M., Devadas Manoharan P., Gobinath D., 2011. Concrete made from ceramic industry waste: Durability propertis, Construction and Building Materials, 25, 2413-2419.

34. Zegardło B., Szeląg M., Ogrodnik P. 2016, Ultrahigh strength concrete made with recycled aggregate from sanitary ceramic wastes. The method of production and the interfacial transition zone. Construction and Building Materials, 122, 736-742.

35. Zegardło B., Szeląg M., Ogrodnik P. 2018a. Concrete resistant to spalling made with recycled aggregate from sanitary ceramic wastes - The effect of moisture and porosity on destructive processes occurring in fire conditions, Construction and Building Materials 173, 58-68.

36. Zegardło B., Brzyski P., Rymuza K., Bombik A. 2018b. Analysis of the effects of aggressive environments simulating municipal sewage on recycled concretes based on selected ceramic waste, Materials 11(12), 2565-2587.

37. Ziolkowski A. 2009. Universal History. Antiquity. Wydawnictwo Naukowe PWN, Warsaw. 